\title{
Legal Status as a Life Course Determinant of Health: Parent Status, Adjudication Stages, and HIV Knowledge Among Highlanders in Thailand
}

Stephanie M. Koning ( $\square$ stephanie.koning@northwestern.edu )

University of Wisconsin-Madison

Amanda Flaim

James Madison College of Public Affairs, Michigan State University

Leo Baldiga

James Madison College, Michigan State University

David A. Feingold

United Nations

\section{Research Article}

Keywords: Legal Status , Birth registration , Citizenship , Statelessness , HIV/AIDS , Health disparities , Thailand, Thai-Myanmar border, Minorities

Posted Date: April 29th, 2021

DOl: https://doi.org/10.21203/rs.3.rs-444186/v1

License: (9) (1) This work is licensed under a Creative Commons Attribution 4.0 International License. Read Full License 


\section{Abstract}

Background: Rising nativism and political volatility worldwide threaten to undermine hard-won achievements in human rights and public health. Risks are particularly acute for hundreds of millions of migrants, minorities, and Indigenous peoples, who face disproportionately high health burdens, including HIV/AIDS, and precarious legal status (LS). While LS is receiving increasing attention as a social determinant of health and HIV, understandings are still limited to select immigrant communities. Its effects on health among stateless communities, particularly in the Global South, remain largely unknown. Moreover, widespread limitations in census measures of LS reduce its complexity to a simplistic citizen/non-citizen binary or insufficient proxies. Thailand's ethnolinguistically diverse highlander population experiences disproportionately high HIV prevalence and comprises one of the world's largest and most protracted cases of statelessness, an acute condition of precarious LS. As such, analysis of LS and health outcomes among highlanders is both critically warranted, and useful as a case study outside of the migration paradigm.

Methods: Drawing on the UNESCO Highland Peoples Survey II (2010), an unprecedented and unique cross-sectional census of highlanders in Thailand, we mobilize complex measures of LS in adjusted ordinal logistic regression models to assess how parent citizenship and LS adjudication over the early life course condition adult HIV knowledge-a key protective factor against transmission $(n=8,079)$.

Results: Adjusted ordinal logistic regression on knowledge scores reveal that parent citizenship predicts more complete knowledge by 32 to 88 percent, depending on ethnic group. This is partially explained by divergent stages of LS adjudication between birth and adulthood, including successful birth registration and adult citizenship acquisition, along with secondary school completion. Precisely how these factors contribute to HIV knowledge varies by ethnic group.

Conclusions: This study advances knowledge of LS outside of the migration paradigm, reveals heretofore unexamined connections between LS and access to public health information, and elucidates how instabilities in LS adjudication stages underlie health inequalities over the life course. Findings indicate that securing success in public health and human rights agendas requires attention to how states deploy LS at birth, and beyond, to structure access and exclusion among migrant and non-migrant communities alike.

\section{Background}

Despite considerable progress, HIV/AIDS persists as a major cause of death globally [1], disproportionately burdening marginalized groups [e.g., 2, 3]. Politically volatile conditions worldwide threaten to undermine human rights and public health achievements in HIV/AIDS eradication, particularly for minorities, Indigenous peoples, and migrants. Millions worldwide are stateless, lacking the recognition or rights of citizenship in any country, and tens of millions more experience precarious legal status (LS): e.g. limited rights to permanent residency, legal employment, and/or social welfare programs $[4,5]$. 
Recent studies have linked precarious LS to adverse impacts on healthcare access [6-10], education [11], violence against women [12], employment and migration outcomes [13-17]. However, even as LS significantly structures life and livelihoods in the 21 st century, it remains largely overlooked in public health research due to significant challenges in data collection and measurement.

Northern Thailand is a valuable study setting for understanding how LS affects health, and HIV transmission specifically. Thailand is renowned for advancing progressive health care agendas and successfully addressing the HIV/AIDS epidemic [18-20]. Yet, the benefits of the HIV/AIDS prevention campaign have not been fully realized by highlanders; the ethnic minorities and Indigenous communities who predominantly live in the mountainous North. Highlanders disproportionately experience both high HIV prevalence and low awareness of HIV transmission relative to lowland ethnic Thais [21, 22]. This is due, in part, to persistent educational barriers for highlander youth and failures to provide culturally and linguistically appropriate information $[23,24]$. Highlanders have also been subjected to precarious LS and protracted statelessness over decades. Yet, how statelessness and precarious LS underlie the HIV/AIDS burden remains underexamined beyond studies of relatively narrow outcomes, such as drug use initiation among select groups [25]. Studying a general HIV risk factor, like accurate knowledge of transmission, in a more representative sample substantially expands current understandings of the problem and structural solutions.

The current study reveals that associations between LS and HIV knowledge are more complex than currently theorized. Specifically, we discover instabilities in stages of LS adjudication over the life course -from parent citizenship to birth registration to adult citizenship confirmation-and education that significantly influence HIV knowledge in adulthood. Moreover, we detect significant ethnic differences in these relationships. These findings inform understandings of LS as a multidimensional and dynamic health determinant. Meanwhile, states around the world variously enact and reinforce precarious LS across and between generations of marginalized communities-e.g., through burdensome and exclusionary evidentiary requirements $[26,27]$.

Our theoretical and empirical contributions join multiple recent calls for attention to LS in public health and medicine $[4,10,28,29]$. Our conceptual model is the first to specify LS adjudication stages and health implications that correspond widely to other states' evidentiary requirements. Thus, it is adaptable for studying precarious LS and health outcomes in other settings. Below, we elaborate on how LS is a social determinant of health and HIV, why highlanders in Thailand present an illuminating study setting, and the current study's approach.

\section{Legal Status as a Health Determinant}

Tens of millions of people worldwide are subjected to precarious LS by states that neglect to, or refuse to, recognize them as citizens or otherwise full, rights-bearing residents. Millions are de jure stateless $[5,30]-$ lacking a legal claim to citizenship in any country. Millions more are effectively stateless, meaning they lack recognition of citizenship, particularly to the state of residence [27]. Precarious LS extends across 
generations when the country of birth alone does not automatically confer the recognition and rights of citizenship (jus soli), but jointly requires citizenship of the parent (jus sanguinis) -as in Thailand. Existing studies regarding the health impacts of LS focus primarily on legal barriers to insurance coverage and government services $[4,7,27,31,32]$. Beyond these, non-citizens without documentation must weigh healthcare needs against fears of encountering stigma in health care settings [28, 33-35], arrest or deportation [36], or both [7, 37, 38]. These fears are substantiated by documented racism and bureaucratically mandated reporting of LS in clinical settings [31,39, 40]. Indirect barriers stem from unstable employment, lower incomes, and language barriers [33, 39, 41, 42].

LS may even act as a structural determinant of health, like poverty or social position [43]. Specifically, precarious LS contributes to social and environmental factors consequential for health: i.e., restricted mobility, poorer educational opportunities, and human rights abuses $[12,44]$. Thus, LS may shape individual health trajectories and population health inequalities that extend intergenerationally. Moreover, social perceptions of who has, or "deserves" LS, may produce spillover health effects among certain racialized groups more broadly $[28,45,46]$. The health impacts of similar forms of structural and interpersonal discrimination are well-documented, and often mediated through inequalities in healthrelated environments, resources, and safety nets [47-49].

\section{Legal status and HIV}

The ongoing HIV/AIDS pandemic stands as devastating global health crisis that both structures, and is structured by, persistent social inequities worldwide [e.g., 50, 51-54]. Yet very few studies have examined the specific role of LS in structuring HIV/AIDS risk. Prior work highlights direct ways that precarious LS is associated with inconsistent access to HIV testing, counseling, and therapeutic services, and findings on HIV status remain mixed [55-58]. Still, very few studies have been able to assess precarious LS as an underlying, structural determinant of HIV infection risk; nor has the relationship between LS and HIV risk been investigated in large, population-based data from areas substantially burdened by statelessness or precarious LS.

Beyond stateless and Indigenous populations being underrepresented in global health research generally, HIV status is often unknown and testing prohibitively expensive in these contexts. Thus, we focus the current study on assessing accurate knowledge of HIV transmission as a necessary step for measuring capacity for protective behavior and infection risk. Although an incomplete measure of risk alone, accurate HIV transmission knowledge has been shown to predict more protective behavior and perceptions of risk [59-62].

In sum, our study contributes a greater understanding of how precarious LS structures HIV risk, by revealing how it structures HIV knowledge in a population acutely affected. In addition to assessing this association overall in the highlander population, we offer a fuller model of how LS early in life fundamentally contributes to intermediate social factors that are already known to be influential for accurate HIV knowledge. We focus specifically on educational attainment, an established predictor of HIV knowledge that then predicts likelihood of testing and serostatus awareness [59, 61, 63, 64], while also 
considering additional important factors in the highland context include rurality, unemployment, age, and cohort. Before elaborating further on the study design, we review relevant historical background for the current situation of statelessness and HIV/AIDS among highlanders below.

\section{Highlanders, Statelessness, and HIV/AIDS in Northern Thailand}

Highlanders in Thailand and across Southeast Asia have variously faced the dual burdens of HIV/AIDS prevalence and precarious LS for decades. The interconnected nature of this dual burden is due, at least partially, to both historical state neglect and development in the highlands. The highland population in Thailand, last estimated in 1996 to number two million [65], includes communities that existed in the country prior to the consolidation of the modern state. Other co-ethnic highland communities arrived in more recent decades, often fleeing war and/or 'development' in neighboring countries. The Thai government officially confers select rights of residency to nine groups of "hill tribes": Karen, Akha, Lahu, Khmu, Lisu, Mien, Htin, Hmong, and Lua. However, highlander coalitions often reject the term as pejorative, and include additional ethnic groups who share common experiences of marginalization and dispossession under broader banners of 'highlanders,' 'ethnic minorities,' and 'Indigenous peoples' [66, 67]. This comprises one of the most ethnolinguistically diverse populations in the world. Coinciding with recent regional conflict and increased demands for land, ethnic Chinese, Burmese, and Thais have also moved into the highlands in recent decades.

The current condition of precarious LS among highlanders in Thailand is historically grounded in a geography of omission. The early censuses of Thailand were used as foundational to future household registration and citizenship claims. However, these did not extend to highland areas [68-70] nor did the first national household registration survey in 1956 [71]. Even today, the Thai census does not include measures of ethnicity and thus forecloses opportunities to update demographic information and resolve conflicting documentation issues among the highlander population. While statelessness apparently mattered little for highlanders in Thailand through the 1960s [72], regional upheaval cast their unregistered status in a new light: highlanders became a focus of national suspicion and concern, and the forests in which they resided were increasingly marked by military and administrative intrusion [73, 74].

As LS and documentation became more significant for highlanders, it simultaneously became more difficult for many to acquire. Many "hill tribe" groups became stigmatized due to growing national concerns over communism, forest destruction, and opium. The Thai government feared the spread of communism from neighboring countries, and the impacts of neighboring civil wars [75], particularly from refugee highlanders. At the same time, under this heightened political tension the government also selectively registered certain Indigenous highlanders at borders as a national security measure [76]. National security concerns also intersected with environmental resource interests in the highlands, as highlanders' shifting cultivation practices were also seen as contributing to both population mobility and a threat to state-owned timber. Additionally, from the mid-1960s on, Thailand came under increasing 
international pressure to suppress opium cultivation in the highlands, which had underpinned the entire highland economy throughout mainland Southeast Asia [77]. The dramatic reduction of opium production that ensued came at significant costs to the health and well-being of highlanders. It devastated livelihoods, fueled displacement, and contributed to the spread of heroin addiction-each posing direct and indirect risks related to the emerging HIV/AIDS crisis [78].

Other general development efforts during this period also fueled and complicated the statelessness problem in the highlands and, consequently, its health implications. Between 1969 and 1999, multiple highlander registration campaigns were initiated. However, instead of conferring citizenship, they were often used to enforce draconian internal identification and border regimes. These further decimated highlanders' traditional livelihoods and limited their capacities to forge new livelihoods in Thailand's booming urban economy $[75,76,79]$. By the early 2000's, highlanders mobilized for citizenship rights and the state ultimately recognized individuals who possessed "full and accurate" documents [14]. However, limitations of past state registration campaigns and many "undocumented" homebirths among highlanders led to protracted LS adjudication and ongoing statelessness among many. Common causes for unresolved LS cases involve barriers and costs to proving parentage/descent, birth on Thai soil, and long-term residency. As many as $20 \%$ of highlanders who are citizens by law remain effectively stateless due to lack of "sufficient" documentation [44].

Given their political and economic marginalization, highlanders have not equally benefited from national health achievements. The delayed national response to HIV/AIDS in the highlands, which emerged in the 1990 's, was devastating $[80,81]$. This was partially due to insufficient surveillance. Initial waves of Thailand's HIV epidemic were attributed to specific risk behaviors and monitored accordingly-sex between men [22], injection drug use[82], and transactional sex [33]. Only later was the elevated risk among highlanders realized, which closely related to their disproportionate representation in jobs associated with injection drug use and sex work in the 1990s and 2000s [21, 22, 33, 83, 84]. Although public health outreach has improved, highlanders continue to face cultural, linguistic, and other social barriers to HIV-related services and accurate information; yet specific barriers vary by ethnic group and village context [41, 85-89].

While these broad structural determinants linking LS to HIV/AIDS in the highlands have been strongly suggested in prior work, many important mechanisms underlying these relationships over the life course remain understudied, including education. Precarious LS early in life has historically hindered educational attainment among highlanders. This has occurred through direct and indirect ways, including LS documents being required for individual enrollment and/or schools in communities with high levels of statelessness being under-resourced or under-staffed [90-93]. More indirect pathways involve state restrictions on land, mobility, and livelihoods that contribute heavily to wealth disparities along LS lines [94], which can pose additional barriers to educational enrollment and attainment among child in affected households. In turn, education has been critical for acquiring citizenship among highlanders born without status [14]. Combined, LS and education are mutually reinforcing in ways that likely affect HIV knowledge. 


\section{Study objectives and approach}

Our study offers a framework of LS as a structural determinant of health that is neither natural nor stable across the life course, or generations. Here, HIV knowledge is the outcome (Fig. 1; measured variables and associations depicted in solid lines). Because Thai citizenship is primarily determined by parent citizenship or birth on Thai soil prior to 1992, we measure multiple LS adjudication stages that occur over the life course: parent citizenship, birth registration, and adult citizenship (confirmed at age 15). We analyze HIV knowledge as a proxy for HIV protection. We include educational attainment as an intermediate factor linking LS to knowledge across life stages.

We test this model using unprecedented data from the highlands. First, we model how adult HIV knowledge is associated with parent citizenship-the earliest stage of LS adjudication measured in our study. In this step, we also evaluate how this association varies across ethnic group. Second, we stage a series of regression analyses to assess the degree to which differences in HIV knowledge by parent citizenship are explained by birth registration, educational attainment, and adult citizenship. Third, to better understand how the inequalities revealed in these analyses vary by ethnicity, we perform these staged regressions separately by ethnic group. This offers insights into how cultural and historical context continue to underlie the relationships presented.

\section{Methods}

\section{Survey data}

The study data were derived from the United Nations Educational, Scientific, and Cultural Organization (UNESCO) Highland Peoples Survey (HPS) II, conducted in 2010 in border villages located in five northernmost and northwesternmost provinces. Funded by UNESCO, and implemented by the Royal Thai Government's Bureau of Social Development (BSD), it is the most comprehensive and expansive survey on statelessness conducted in the world. It was designed to measure complex dynamics of LS and understand the effects of statelessness on a range of life and livelihood outcomes. It substantially expanded the coverage of villages relative to the HPS I (2005), and includes information on multiple, unique measures of LS, as well as education, migration, family relationships, and health in the highlands. Sampling criteria were based on village proximity to the international border $(\leq 20 \mathrm{~km})$. All households within villages in Chiang Rai, Chiang Mai, and Mae Hong Son provinces were sampled $(n=179)$, along with $25 \%$ of households in villages in Tak and Kanchanaburi provinces $(n=113)$. The sampling frame, generated by the Center for Hill Tribe Development and Welfare, was a full roster of highland villages. The HPS II sample included 292 villages and 15,396 households. The overall response rate was exceptionally high (99\%), which was attributed to villagers' keen interest in LS issues [14].

Questionnaires were administered in person by trained BSD staff to adult representatives of each household, and are published in the original data collection study [14]. The data collection protocol followed contemporary UNESCO ethical guidelines for human subjects research among indigenous 
peoples, with informed consent in local languages provided in two venues. First, prior to implementing each survey, surveyors met with villagers in open fora to explain, in detail, the objectives and limitations of the survey, enabling community members and representatives to ask clarifying questions and to register concerns about the survey in a collective, safe environment. Second, oral consent was acquired by each individual participant prior to initiating surveys. Women were encouraged to be representatives/respondents. Interviews were conducted in a space of each respondent's choosing and in respondents' preferred languages, including highlander languages and northern Thai, each of which were pretested. Upon data entry all data were completely de-identified. The current analysis of these anonymized data was completed at University of Wisconsin (UW) as non-human subjects research, with exemption status confirmed by the UW Institutional Review Board.

Questionnaires were administered in person by trained BSD staff to adult representatives of each household, with informed consent, and are published in the original data collection study [14]. Data collection protocol followed contemporary UNESCO ethical guidelines for human subjects research. Women were encouraged to be representatives/respondents. Interviews were conducted in respondents' preferred languages, including highlander languages and northern Thai. Each language was pretested.

The current study analysis is limited to Lahu, Karen, Akha, Hmong, Lisu, and Mien people, due to subsample size. We also only included individuals born in Thailand to focus on structural barriers specific to LS adjudication in Thailand over the life course. The data made available to us for the current analysis was completely de-identified. The current study analysis was completed at University of Wisconsin (UW) as non-human subjects research, with exemption status confirmed by the UW Institutional Review Board.

Table 1 summarizes sample characteristics, comparing highlanders and ethnic Thais. Missingness for all analytical variables ranged from 0 to 5 percent (online appendix; Table A1).

\section{Measures}

Respondents' HIV knowledge scores were calculated as sums of correct responses to questions regarding HIV transmission, adapted from the cross-culturally validated Demographic and Health Survey instrument (2008-2013). Respondents answered the following questions separately: Can you contract HIV/AIDS from: sharing a needle with someone who has HIV/AIDS; a mosquito or insect bite; from a mother's womb to her child; eating with someone who has HIV/AIDS; having sex with someone who has HIV/AIDS without using a condom; kissing a person who has HIV/AIDS?

The survey requested information on each parent's citizenship status, including those deceased and separated at the time of the survey. We constructed a single variable to indicate whether at least one parent had citizenship. In our staged regressions the following binary variables served as intermediate stages of LS adjudication and education: birth registration, secondary school completion, and adult citizenship. 
Wealth was measured in quartiles based on a factor analysis of house materials [94]. We categorized age groups as follows: $17-25,26-35,36-45,46-55$, and 56 years old and older.

\section{Analysis}

To contextualize our analysis, we described HIV knowledge between highlander and ethnic Thai respondents in the sample (Table 1). In models, we then excluded ethnic Thai respondents because nearly all had a parent with citizenship (i.e., no internal comparison group). To model differences by parent citizenship, we performed ordinal logistic regression, a generalized linear mixed model allowing for nonlinear trends in knowledge scores, using likelihood estimation with Laplace approximation, in SAS 9 (PROC GLIMMIX). To account for village-level differences in HIV knowledge, we included village random intercepts (more details in online appendix). We adjusted for respondent sex, age, and ethnicity. To account for differences in the impact of parent citizenship on HIV knowledge by ethnicity, we included interaction terms between parent citizenship and indicators for each ethnic group, which were statistically significant (Likelihood ratio: $\left.X^{2}(4)=17.0, p=0.002\right)$.

To assess whether respondents' prior birth registration, educational attainment, and adult citizenship accounted for differences by parent citizenship we built staged regressions from the original model. Based on evidence in our sample that LS is differentially associated with HIV by ethnicity, we performed this analysis separately for the three largest ethnic groups in the sample (Karen, Lahu, and Akha) and included two-way interaction terms between parent citizenship and each intermediate variable added. To isolate differences attributable to experiences of LS adjudication, beyond what may be driven by cohort and age differences, we limited each subgroup analysis to respondents 35 years old and younger. Using these models, we estimated conditional predicted probabilities for obtaining each HIV knowledge score, along with probability ratios between respondents with and without a citizen parent, averaged across men and women and conditioned on mean age and median wealth.

\section{Results}

\section{Parent Legal Status and HIV Knowledge}

First, highlander and ethnic Thai respondents living in similarly remote border villages possess strikingly different HIV knowledge (Table 1). Among highlanders, differences in knowledge by parent citizenship were also sizeable and significant. The difference attributable to parent citizenship was parsed between multiple coefficients (log odds ratios in Table 2). Overall, respondents with at least one citizen parent were more likely to score higher. Variation by ethnic group is reflected in the interaction coefficients. Relative to Karen people, other ethnic groups experienced a smaller advantage associated with parent citizenship. This was in addition to the predominantly negative main effects associated with belonging to a nonKaren ethnic minority group. Men and younger respondents were more likely to score higher. Additional summary statistics are available online. 
Table 1

Comparison of highlander and ethnic Thai HPS II respondent.

\begin{tabular}{|c|c|c|}
\hline & Highlander & Thai \\
\hline Total (n) & 8,079 & 1,866 \\
\hline \multicolumn{3}{|c|}{ HIV Knowledge Score $(0-6)$} \\
\hline Mean & 3.1 & 4.2 \\
\hline Median & 3 & 5 \\
\hline $100 \%$ correct & $19 \%$ & $30 \%$ \\
\hline \multicolumn{3}{|l|}{ LS adjudication } \\
\hline Parent with citizenship & $71 \%$ & $96 \%$ \\
\hline Birth registered & $31 \%$ & $73 \%$ \\
\hline Adult citizenship & $86 \%$ & $99 \%$ \\
\hline \multicolumn{3}{|c|}{ Highest education level completed } \\
\hline Primary & $19 \%$ & $11 \%$ \\
\hline Secondary & $9 \%$ & $17 \%$ \\
\hline \multicolumn{3}{|l|}{ Socio-demographic } \\
\hline \multicolumn{3}{|l|}{ Age } \\
\hline $17-25$ & $12 \%$ & $5 \%$ \\
\hline $26-35$ & $25 \%$ & $15 \%$ \\
\hline $36-45$ & $27 \%$ & $23 \%$ \\
\hline $46-55$ & $19 \%$ & $26 \%$ \\
\hline $56+$ & $17 \%$ & $30 \%$ \\
\hline Male sex & $59 \%$ & $56 \%$ \\
\hline \multicolumn{3}{|l|}{ Ethnicity } \\
\hline Karen & $44 \%$ & - \\
\hline Lahu & $30 \%$ & - \\
\hline Akha & $13 \%$ & - \\
\hline Hmong & $9 \%$ & - \\
\hline Lisu & $3 \%$ & - \\
\hline
\end{tabular}




\begin{tabular}{|lll|}
\hline & Highlander & Thai \\
\hline Wealth quartile & & \\
\hline 1: Palm/thatch roof & $33 \%$ & $4 \%$ \\
\hline 2: Metal/other roof & $24 \%$ & $30 \%$ \\
\hline 3: Tile roof, no satellite & $25 \%$ & $37 \%$ \\
\hline 4: Tile roof \& satellite & $17 \%$ & $30 \%$ \\
\hline
\end{tabular}


Table 2

\section{Ordinal regression results.}

Intercepts (log odds), coefficients (log odds ratios), and $95 \%$ confidence intervals $(\mathrm{Cl})$. Type III tests of fixed effects for each independent variable were statistically significant $(\mathrm{p}<0.01)$.

\begin{tabular}{|c|c|c|c|}
\hline & Point estimates & $95 \% \mathrm{Cl}$ & \\
\hline \multicolumn{4}{|l|}{ HIV Score Intercepts } \\
\hline 1 & 0.50 & $(0.05$ & $0.95)$ \\
\hline 2 & 0.33 & $(-0.12$ & $0.78)$ \\
\hline 3 & -0.08 & $(-0.53$ & $0.37)$ \\
\hline 4 & -0.81 & $(-1.26$ & $-0.36)$ \\
\hline 5 & -1.47 & $(-1.92$ & $-1.02)$ \\
\hline 6 & -2.58 & $(-2.58$ & $-2.13)$ \\
\hline \multicolumn{4}{|l|}{ Coefficients } \\
\hline Parent citizenship & 0.62 & $(0.42$ & $0.82)$ \\
\hline \multicolumn{4}{|l|}{ Ethnic group } \\
\hline Karen & (Reference) & & \\
\hline Lahu & -0.67 & $(-1.18$ & $-0.16)$ \\
\hline Akha & -0.18 & $(-0.71$ & $0.36)$ \\
\hline Hmong & 0.08 & $(-0.54$ & $0.70)$ \\
\hline Lisu & -0.46 & $(-1.10$ & $0.18)$ \\
\hline \multicolumn{4}{|l|}{ Age group } \\
\hline Over 55 & (Reference) & & \\
\hline $46-55$ & 0.22 & (0.08, & $0.36)$ \\
\hline $36-45$ & 0.46 & (0.33, & $0.59)$ \\
\hline $26-35$ & 0.89 & (0.75, & 1.02) \\
\hline $15-25$ & 1.07 & (0.91, & 1.23) \\
\hline \multicolumn{4}{|l|}{ Sex } \\
\hline Male & 0.36 & (0.27, & $0.45)$ \\
\hline
\end{tabular}




\begin{tabular}{|llll|}
\hline \multicolumn{5}{|c|}{ Point estimates } & $95 \% \mathrm{Cl}$ \\
\hline Wealth & $(0.16$, & $0.25)$ \\
\hline Wealth index & 0.20 & \\
\hline \multicolumn{3}{|l}{ Parent citizenship * } & \\
\hline Karen & (Reference) & \\
Lahu & -0.33 & $(-0.59$, & $-0.06)$ \\
Akha & -0.59 & $(-0.89$, & $-0.29)$ \\
Hmong & -0.48 & $(-0.90$, & $-0.06)$ \\
Lisu & -0.25 & $(-0.75$, & $0.26)$ \\
\hline
\end{tabular}

\section{Intermediate Social Determinants: Birth registration, education, and adult citizenship}

As expected, birth registration, educational attainment, and adult citizenship each accounted for significant proportions of the differences in HIV knowledge by parent citizenship, based on staged model results. However, the relative impacts of these factors varied by ethnic group. Figure 2 summarizes results from the ethnic subgroup analyses. Among Karen people, parent citizenship was associated with an $88 \%$ greater probability of a perfect HIV knowledge score. In comparison, parent citizenship was associated with a $45 \%$ and $32 \%$ greater probability of a perfect score among Lahu and Akha respondents, respectively. Eighty-one percent of the parent citizenship advantage among Karen respondents was explained by birth registration, educational attainment, and adult citizenship. Among Lahu and Akha respondents, the same intermediate variables accounted for $47 \%$ and $97 \%$ percent of the parent citizenship advantage. Complete model coefficients and tests are online.

\section{Discussion}

HIV transmission knowledge is a critical resource for minimizing infection risks. For communities experiencing high HIV prevalence, like highlanders in Thailand, this resource remains dangerously elusive $[41,88]$. Statelessness and precarious LS have largely been ignored as contributors to this problem, among highlanders and generally. Our study demonstrates the fundamental role of LS as a complex social condition that shapes health-relevant exposures over the individual life course, starting with parent LS. Specifically, this research challenges conventional methodological and theoretical models that frame LS as a static binary of citizen/non-citizen. Furthermore, it expands understandings of social and cultural disparities in HIV knowledge gaps, and potentially in health inequalities more broadly.

Importantly, our study found LS to be neither simple nor simply associated with accurate HIV/AIDS knowledge. Rather, parent LS structured HIV knowledge via subsequently linked, yet unstable, stages of 
the adjudication process: birth registration certification and adult citizenship. By conceptualizing LS as a series of stages, we revealed instabilities therein, which corresponded to differential influence on HIV knowledge and education. First, we found an enduring association between parent citizenship and HIV knowledge as an adult, independent of age, sex, and wealth. This association was attenuated by birth registration and by official confirmation of citizenship. Therefore, our findings suggest that each stage of LS determination over the early life-course had a significant independent and cumulative impact on HIV knowledge. However, there were still lasting impacts of parent citizenship, or lack thereof, among most groups. This finding suggests that LS carries influence both over the individual life course and across generations. These implicated pathways will likely be pivotal in the perpetuation or amelioration of future HIV inequalities.

Furthermore, we show how parent LS and subsequent adjudication stages variously structured HIV knowledge via barriers to education and other resources early in life. Prior research has demonstrated the protective role of educational attainment in promoting personal HIV knowledge and HIV risk reduction [42, 95]. Additionally, parent citizenship and birth registration have been shown to be highly predictive of educational attainment among highlanders in Thailand $[14,90]$. To our knowledge, this study is the first to connect these pathways. Evidence from all three of the largest highlander groups indicated that educational attainment accounted for at least half of the HIV knowledge advantage attributed to parent citizenship. Other mediators that link parent citizenship and knowledge remain largely unstudied and may include education quality, access to health information through educators or otherwise informed social networks, and mobility.

Finally, our study revealed significant ethnic differences in HIV knowledge and its association with LS adjudication. Lahu, Akha, Hmong, and Lisu respondents were less likely than Karen respondents to answer HIV transmission questions correctly. Prior studies have similarly documented differences in HIV knowledge between ethnic minorities in northern Thailand [41, 88], yet none assess these differences by citizenship. First, the parent citizen advantage was weaker among Lahu and Akha respondents, compared to Karen respondents. Second, this advantage was explained by subsequent LS adjudication stages to different degrees between ethnic subgroup. These different patterns of attenuation could be explained by ethnic differences in how strongly parent citizenship predicts subsequent LS adjudication, educational attainment, or both. They could also be explained by LS or educational attainment being more predictive of adult HIV knowledge among certain ethnic groups. More research is needed to contextualize these findings and better understand how LS may inform, exacerbate, or buffer other barriers related to ethnicity, culture, and language. This need is further supported by prior research on statelessness in Thailand with respect to variations in ethnic groups' experiences with civil registration and identification policies, land dispossession, access to education, free mobility, and safe, equitable employment compensation $[44,76,92,94,96]$.

\section{Limitations}


This work is not without limitations. First, HIV knowledge as the study outcome was not a direct measure of risk and is incomplete on its own. Future work should expand on other HIV-related outcomes, and health more generally. Second, because findings from this study derived from cross-sectional survey data, associations were correlational rather than causal. It is possible that the association between LS and education was bidirectional. In some cases, educational attainment may have affected parent citizenship. Ethnographic evidence suggests this is plausible, but not likely driving estimates $[14,79]$. Authorities are discouraged from recognizing the citizenship of anyone who cannot prove their birth in the country, thus undermining claims of older generations who were mostly born at home and lack certification of birth or early residence [94]. Still, the limitations of the current study warrant future research, including pathway analyses with updated and longitudinal data, that would further elucidate mechanisms linking LS and HIV/health over the life course among affected populations, families, and individuals. This continued work is critical for understanding the complexity of specific situations and adequately inform future interventions and policy.

Additional study limitations relate to respondent selection. Due to resource limitations and the survey design, only one household representative answered the HIV questions. Thus, the generalizability of findings is limited. However, the respondents still comprise an important subpopulation: household leaders and parents of the next generation. Based on the survey sampling, findings may not be generalizable to other minority, Indigenous, and stateless people in more urban settings either: e.g., where LS may not similarly constrain access to health information. Regardless of these limits to generalizability, understanding how LS affected health and knowledge in this border population remains critically important.

\section{Conclusions}

Growing global concerns regarding statelessness and precarious LS carry grave implications in the ongoing HIV/AIDS epidemic, and health and human rights more broadly. Yet, this issue is often obscured when LS is theorized as a simple measure and siloed into immigrant health research. Our study highlights the health implications of instabilities in LS adjudication relevant to numerous contexts beyond the migration paradigm. In doing so, we offer a foundational analysis and adaptable approach for future studies that focus in greater detail on context-specific mechanisms over the life course. This is especially relevant with the emergence and re-emergence of authoritarian regimes and related political volatility, alongside enhanced state surveillance and land seizure efforts. If these persist, legal exclusion will continue to shape the vulnerabilities of Indigenous peoples, second-generation immigrants, and other marginalized and minoritized peoples worldwide [27]. Thus, more analyses of LS adjudication and health, including through mechanisms involving education, are necessary in Thailand and elsewhere to extend this work to other contexts of bureaucratic violence and legal erasure.

Our findings also emphasize the importance of promoting human rights, education, and health as early in life as possible. Withholding any path to full citizenship rights at birth in contexts such as Thailand equates to withholding the full protection of one's human rights, including health and education as rights. 
Recent efforts to address these problems include promoting universal birth registration campaigns as global health interventions. Yet, while birth registration is indeed associated with health advantages, our findings do not necessarily endorse interventions that simply prioritize documentation alone. As evidenced in the ongoing experiences of highlanders in Thailand, even ostensibly depoliticized campaigns for registration may still inadvertently facilitate erasures and structural exclusions for generations to come. Considering our study context and others, more careful design and interrogation of specific interventions and policy reform are still warranted. Ultimately, to intervene on legal exclusion as a structural determinant of health and inequities, considerations of how to expand and equalize health, education, and social service access in ways unobstructed by individual LS adjudication processes and related discrimination are also needed.

\section{Abbreviations}

HIV: Human immunodeficiency virus

AIDS: Acquired immunodeficiency syndrome

LS: Legal status

UNESCO: United Nations Educational, Scientific, and Cultural Organization

HPS: Highland Peoples Survey

Cl: Confidence interval

C: Citizenship

PC: Parent citizenship

BR: Birth registration

Ed: Education

\section{Declarations}

\section{Ethics approval and consent to participate}

The study data were derived from the United Nations Educational, Scientific, and Cultural Organization (UNESCO) Highland Peoples Survey (HPS) II, conducted in 2010 by trained staff of the Thailand Bureau of Social Development. This was not a health survey and did not collect personal health information. Nonetheless, trained field staff obtained documented informed consent before conducting questionnaireassisted interviews with each participating adult household representative. Data collection protocol followed contemporary UNESCO ethical guidelines for research with Indigenous populations. No identifiable information was included in the final dataset made available to the study authors. The current 
study analysis was completed at University of Wisconsin (UW) as non-human subjects research, with exemption status confirmed by the UW Institutional Review Board (UW IRB ID: 2012-0872).

\section{Consent for publication}

Not applicable.

\section{Availability of data and materials}

The data that support the findings of this study are available from the United Nations Educational, Scientific, and Cultural Organization (UNESCO) but restrictions apply to the availability of these data and so are not publicly available. Data are however available from the authors upon reasonable request and with permission of UNESCO.

\section{Competing interests}

The authors declare that they have no competing interests.

\section{Funding}

This research uses data from the UNESCO Highland Peoples Survey II, which was developed by the UNESCO HIV/AIDS and Trafficking Project and implemented by the Royal Thai Government's Bureau of Social Development and Human Security with support of grants from the Office of Human Rights of the British Embassy, Bangkok, and the Canadian International Development Agency (CIDA). The writing of the manuscript was made possible through individual author support. The lead author's training and time during the writing of this article was supported by the Mustard Seed Foundation and through grants awarded to the Center for Demography and Ecology by the Eunice Kennedy Shriver National Institute of Child Health and Human Development (P2C HD047873) and to the Center for Demography of Health and Aging by the National Institute on Aging (P30 AG17266, T32 AG00129) at the University of WisconsinMadison. Co-authors' time was additionally supported by the National Research Council of Thailand, a Fulbright-Hays Dissertation Fellowship, the Southeast Asian Studies Program at Cornell University, the Mario Einaudi Center for International Studies, the Asian Studies Center at Michigan State University, and the Spunk Fund Inc. None of the funding bodies listed were involved in the writing of the manuscript. The findings and conclusions in this article are those of the authors, and do not necessarily represent the official position of UNESCO or any other institutions listed.

\section{Authors' contributions}


SK analyzed and interpreted the survey data. SK, AF, and DF co-designed questions used in the survey. $\mathrm{SK}, \mathrm{AF}, \mathrm{LB}$, and DF each contributed to the literature review and writing of the manuscript. All authors read and approved the final manuscript.

\section{Acknowledgements}

Not applicable

\section{Authors' information}

SK conducted this study as a predoctoral research training fellow at the University of Wisconsin-Madison. She is currently a postdoctoral research fellow at Northwestern University's Institute for Policy Research. She possesses a Ph.D. in population health and M.S. in sociology. Her research focuses on health disparities in Southeast Asia and the U.S. using survey, statistical, and ethnographic methods, and has been supported by the NIH, UNESCO, and CIDA. AF is Assistant Professor at James Madison College and the Department of Sociology at Michigan State University. Her ethnographic and survey research examines how legal status and related deprivations are produced and experienced among Indigenous and minority communities in Southeast Asia. AF has served as a lead research consultant to projects on legal status for UNHCR, UNESCO, and UNICEF. LB is a U.S. Fulbright research fellow studying health and migration among Indigenous and minority communities in Southeast Asia. LB holds a B.A. from James Madison College at Michigan State University. DF is Director of the Ophidian Research Institute. He holds an MA in SE Asian Studies and a PH.D. in anthropology. For 15 years, he developed and directed the UNESCO (Bangkok) regional HIV/AIDS and Trafficking Program and the UNESCO Highland Citizenship Project. His work has been supported by NIDA, NIMH, NEH, The John D. and Catherine T. MacArthur Foundation and The Spunk Fund Inc.

\section{References}

1. UNAIDS: Global HIV and AIDS statistics 2019 Fact sheet. In.; 2019.

2. Farmer P: Infections and inequalities: The modern plagues: Univ of California Press; 2001.

3. Rice WS, Logie CH, Napoles TM, Walcott M, Batchelder AW, Kempf M-C, Wingood GM, Konkle-Parker DJ, Turan B, Wilson TE: Perceptions of intersectional stigma among diverse women living with HIV in the United States. Soc Sci Med 2018, 208:9-17.

4. Kingston LN, Cohen EF, Morley CP: Debate: Limitations on universality: the" right to health" and the necessity of legal nationality. BMC Int Health Hum Rights 2010, 10(1):1-12.

5. UNHCR: Global Trends: Forced Displacement in 2019. In. Copenhagen, Denmark: Office of the United Nations High Commissioner for Refugees; 2020.

6. Blondell SJ, Kitter B, Griffin MP, Durham J: Barriers and facilitators to HIV testing in migrants in highincome countries: a systematic review. AIDS Behav 2015, 19(11):2012-2024. 
7. Harris J: Uneven inclusion: consequences of universal healthcare in Thailand. Citizenship Studies 2013, 17(1):111-127.

8. Koning SM, Scott K, Conway JH, Palta M: Reproductive health at conflict borders: a cross-sectional survey of human rights violations and perinatal outcomes at the Thai-Myanmar border. Conflict and health 2021, 15(1):1-10.

9. Van Natta M, Burke NJ, Yen IH, Fleming MD, Hanssmann CL, Rasidjan MP, Shim JK: Stratified citizenship, stratified health: Examining latinx legal status in the US healthcare safety net. Soc Sci Med 2019, 220:49-55.

10. Torres JM, Young M-ED: A life-course perspective on legal status stratification and health. SSMpopulation health 2016, 2:141-148.

11. Greenman E, Hall M: Legal status and educational transitions for Mexican and Central American immigrant youth. Soc Forces 2013, 91(4):1475-1498.

12. Koning SM: Displacement contexts and violent landscapes: How conflict and displacement structure women's lives and ongoing threats at the Thai-Myanmar border. Soc Sci Med 2019, 240:112557.

13. Feingold DA: Trading Women. In. Philadelphia, USA: www.der.org; 2003.

14. Flaim A: No Land's Man: Sovereignty, Legal Status, and the Production of Statelessness among Highlanders in Northern Thailand. 2015.

15. Wilhelm M, Kadfak A, Bhakoo V, Skattang K: Private governance of human and labor rights in seafood supply chains-The case of the modern slavery crisis in Thailand. Marine Policy 2020, 115:103833.

16. Meyer SR, Robinson WC, Abshir N, Mar AA, Decker MR: Trafficking, Exploitation and Migration on the Thailand-Burma Border: A Qualitative Study. International Migration 2015, 53(4):37-50.

17. IOM: Thailand Migration Report 2019. In. Bangkok, Thailand; 2019.

18. Siraprapasiri T, Ongwangdee S, Benjarattanaporn P, Peerapatanapokin W, Sharma M: The impact of Thailand's public health response to the HIV epidemic 1984-2015: understanding the ingredients of success. Journal of virus eradication 2016, 2:7-14.

19. Thisyakorn U: Elimination of mother-to-child transmission of HIV: lessons learned from success in Thailand. Paediatrics and international child health 2017, 37(2):99-108.

20. Wong J, Macikunas A, Manduric A, Dawkins J, Dhunna S: Reaching the Hard to Reach in Thailand: Eliminating Mother-To-Child HIV Transmission. Health Systems \& Reform 2020, 6(1):e1625498.

21. Beyrer C, Celentano D, Suprasert S, Sittitrai W, Nelson K, Kongsub B, Phanupak P: Widely varying HIV prevalence and risk behaviours among the ethnic minority peoples of northern Thailand. AIDS Care 1997, 9(4):427-439.

22. Guadamuz TE, Kunawararak P, Beyrer C, Pumpaisanchai J, Wei C, Celentano DD: HIV prevalence, sexual and behavioral correlates among Shan, Hill tribe, and Thai male sex workers in Northern Thailand. AIDS Care 2010, 22(5):597-605. 
23. Feingold DA: Sex, Drugs and the IMF: Some Implications of" Structural Readjustmentn for the Bade in Heroin, Girls and Women in the Upper Mekong Region. Refuge: Canada's Journal on Refugees 1998:4-10.

24. Ford N, Koetsawang S: The socio-cultural context of the transmission of HIV in Thailand. Soc Sci Med 1991, 33(4):405-414.

25. Chomchoei C, Apidechkul T, Wongnuch P, Tamornpark R, Upala P, Nongkhai MPN: Perceived factors influencing the initiation of methamphetamine use among Akha and Lahu youths: a qualitative approach. BMC Public Health 2019, 19(1):1-11.

26. Bhabha J: Arendt's Children: Do Today's Migrant Children have a right to have rights. Hum RTs $Q$ 2009, 31:410.

27. Lawrance BN, Stevens J: Citizenship in Question: Evidentiary Birthright and Statelessness: Duke University Press; 2017.

28. Asad AL, Clair M: Racialized legal status as a social determinant of health. Soc Sci Med 2018, 199:19-28.

29. Nolan LB, Bloom DE, Subbaraman R: Legal status and deprivation in urban slums over two decades. Economic and political weekly 2018, 53(15):47.

30. IOM: World Migration Report 2020. In. Geneva, Switzerland; 2020.

31. Martinez O, Wu E, Sandfort T, Dodge B, Carballo-Dieguez A, Pinto R, Rhodes S, Moya E, Chavez-Baray $\mathrm{S}$ : Evaluating the impact of immigration policies on health status among undocumented immigrants: a systematic review. Journal of immigrant and minority health 2015, 17(3):947-970.

32. Suphanchaimat R, Putthasri W, Prakongsai P, Tangcharoensathien V: Evolution and complexity of government policies to protect the health of undocumented/illegal migrants in Thailand-the unsolved challenges. Risk Manag Healthc Policy 2017, 10:49.

33. Kilmarx PH, Supawitkul S, Wankrairoj M, Uthaivoravit W, Limpakarnjanarat K, Saisorn S, Mastro TD: Explosive spread and effective control of human immunodeficiency virus in northernmost Thailand: the epidemic in Chiang Rai province, 1988-99. AIDS 2000, 14(17):2731-2740.

34. Korinek K, Smith KR: Prenatal care among immigrant and racial-ethnic minority women in a new immigrant destination: exploring the impact of immigrant legal status. Soc Sci Med 2011, 72(10):1695-1703.

35. Larchanché S: Intangible obstacles: health implications of stigmatization, structural violence, and fear among undocumented immigrants in France. Soc Sci Med 2012, 74(6):858-863.

36. Chavez LR: Undocumented immigrants and their use of medical services in Orange County, California. Soc Sci Med 2012, 74(6):887-893.

37. Castañeda H, Holmes SM, Madrigal DS, Young M-ED, Beyeler N, Quesada J: Immigration as a social determinant of health. Annu Rev Public Health 2015, 36:375-392.

38. Feingold DA: A Right to Belong. In.: Documentary Educational Resources (DER); 2002. 
39. Alvarez-del Arco D, Monge S, Azcoaga A, Rio I, Hernando V, Gonzalez C, Alejos B, Caro AM, PerezCachafeiro S, Ramirez-Rubio O: HIV testing and counselling for migrant populations living in highincome countries: a systematic review. The European Journal of Public Health 2013, 23(6):10391045.

40. Holmes SM: An ethnographic study of the social context of migrant health in the United States. PLoS Med 2006, 3(10):e448.

41. Kunstadter P: Ethnicity, socioeconomic characteristics and knowledge, beliefs and attitudes about HIV among Yunnanese Chinese, Hmong, Lahu and Northern Thai in a north-western Thailand border district. Culture, health \& sexuality 2013, 15(sup3):S383-S400.

42. Musumari PM, Chamchan C: Correlates of HIV testing experience among migrant workers from Myanmar residing in Thailand: a secondary data analysis. PLoS One 2016, 11(5):e0154669.

43. Link BG, Phelan J: Social conditions as fundamental causes of disease. J Health Soc Behav 1995:80-94.

44. Flaim A: Problems of Evidence, Evidence of Problems: Expanding Citizenship and Reproducing Statelessness among Highlanders in Northern Thailand. In: Citizenship in Question: Evidentiary Birthright and Statelessness. edn.; 2017: 147-164.

45. Philbin MM, Flake M, Hatzenbuehler ML, Hirsch JS: State-level immigration and immigrant-focused policies as drivers of Latino health disparities in the United States. Soc Sci Med 2018, 199:29-38.

46. Sabo S, Shaw S, Ingram M, Teufel-Shone N, Carvajal S, De Zapien JG, Rosales C, Redondo F, Garcia G, Rubio-Goldsmith R: Everyday violence, structural racism and mistreatment at the US-Mexico border. Soc Sci Med 2014, 109:66-74.

47. Farmer PE, Nizeye B, Stulac S, Keshavjee S: Structural violence and clinical medicine. The Social Medicine Reader, Volume II, Third Edition 2019:156-169.

48. Krieger N: Discrimination and health inequities. Int J Health Serv 2014, 44(4):643-710.

49. Williams DR, Mohammed SA, Leavell J, Collins C: Race, socioeconomic status and health: Complexities, ongoing challenges and research opportunities. Ann N Y Acad Sci 2010, 1186:69.

50. Khan S, Lorway R, Chevrier C, Dutta S, Ramanaik S, Roy A, Bhattacharjee P, Mishra S, Moses S, Blanchard J et al: Dutiful daughters: HIV/AIDS, moral pragmatics, female citizenship and structural violence among Devadasis in northern Karnataka, India. Global Public Health 2018, 13(8):1065-1080.

51. Farmer P: On suffering and structural violence: A view from below. Daedalus 1996:261-283.

52. Farmer P: Pathologies of power: rethinking health and human rights. Am J Public Health 1999, 89(10):1486-1496.

53. Farmer P, Bourgois P, Scheper-Hughes N, Fassin D, Green L, Heggenhougen H, Kirmayer L, Wacquant L, Farmer P: An anthropology of structural violence. Current Anthropology 2004, 45(3):305-325.

54. Storm M, Deuba K, Damas J, Shrestha U, Rawal B, Bhattarai R, Marrone G: Prevalence of HIV, syphilis, and assessment of the social and structural determinants of sexual risk behaviour and health service utilisation among MSM and transgender women in Terai highway districts of Nepal: findings based 
on an integrated biological and behavioural surveillance survey using respondent driven sampling. BMC Infect Dis 2020, 20:1-14.

55. Davis A, Terlikbayeva A, Terloyeva D, Primbetova S, El-Bassel N: What prevents central Asian migrant workers from accessing HIV testing? Implications for increasing HIV testing uptake in Kazakhstan. AIDS Behav 2017, 21(8):2372-2380.

56. Marukutira T, Block L, Alwano MG, Behel S, Jarvis JN, Chakalisa U, Powis K, Novitsky V, Bapati W, Wang $\mathrm{H}$ : Comparison of knowledge of HIV status and treatment coverage between non-citizens and citizens: Botswana Combination Prevention Project (BCPP). PLoS One 2019, 14(8):e0221629.

57. Poon KK, Dang BN, Davila JA, Hartman C, Giordano TP: Treatment outcomes in undocumented Hispanic immigrants with HIV infection. PLoS One 2013, 8(3):e60022.

58. Shearer K, Clouse K, Meyer-Rath G, MacLeod W, Maskew M, Sanne I, Long L, Fox MP: Citizenship status and engagement in HIV care: an observational cohort study to assess the association between reporting a national ID number and retention in public-sector HIV care in Johannesburg, South Africa. BMJ open 2017, 7(1):e013908.

59. Alemu YM, Ambaw F, Wilder-Smith A: Utilization of HIV testing services among pregnant mothers in low income primary care settings in northern Ethiopia: a cross sectional study. BMC Pregnancy Childbirth 2017, 17(1):1-8.

60. Barden-O'Fallon JL, deGraft-Johnson J, Bisika T, Sulzbach S, Benson A, Tsui AO: Factors associated with HIV/AIDS knowledge and risk perception in rural Malawi. AIDS Behav 2004, 8(2):131-140.

61. Fang D, Sun R, Wilson JR: Joint modeling of correlated binary outcomes: The case of contraceptive use and HIV knowledge in Bangladesh. PLoS One 2018, 13(1):e0190917.

62. Kuehne A, Koschollek C, Santos-Hövener C, Thorlie A, Müllerschön J, Mputu Tshibadi C, Mayamba P, Batemona-Abeke H, Amoah S, Wangare Greiner V: Impact of HIV knowledge and stigma on the uptake of HIV testing-Results from a community-based participatory research survey among migrants from sub-Saharan Africa in Germany. PLoS One 2018, 13(4):e0194244.

63. Ciampa PJ, Skinner SL, Patricio SR, Rothman RL, Vermund SH, Audet CM: Comprehensive knowledge of HIV among women in rural Mozambique: development and validation of the HIV knowledge 27 scale. PLoS One 2012, 7(10):e48676.

64. Kawichai S, Celentano DD, Chariyalertsak S, Visrutaratna S, Short O, Ruangyuttikarn C, Chariyalertsak C, Genberg B, Beyrer C: Community-based voluntary counseling and testing services in rural communities of Chiang Mai Province, Northern Thailand. AIDS Behav 2007, 11(5):770-777.

65. Aguettant JL: Impact of population registration on hilltribe development in Thailand. Asia-Pacific Population Journal 1996, 11(4):47-72.

66. Baird IG, Leepreecha P, Yangcheepsutjarit U: Who should be considered 'Indigenous'? A survey of ethnic groups in northern Thailand. Asian Ethnicity 2017, 18(4):543-562.

67. Morton MF, Baird IG: From Hill tribes to Indigenous Peoples: The localisation of a global movement in Thailand. Journal of Southeast Asian Studies 2019, 50(1):7-31. 
68. Boonperm J: Population and Housing Census in Thailand. In: ASEAN Meeting. Siem Reap, Cambodia; 2010.

69. Grabowsky V: The Thai census of 1904: Translation and analysis. Journal of The Siam Society Vol 1996, 84(Part 1).

70. Sternstein L: A critique of Thai population data. Pacific Viewpoint 1965, 6(1):15-38.

71. Feingold DA: Trafficking, Trade, and Migration: Mapping Human Trafficking in the Mekong Region. An Atlas of Trafficking in Southeast Asia: The Illegal Trade in Arms, Drugs, People, Counterfeit Goods and Natural Resources in Mainland Southeast Asia 2011.

72. McKinnon J, Bhruksasri W: Highlanders of Thailand. Oxford, UK: Oxford University Press; 1983.

73. Geddes WR: Research and the Tribal Research Centre. Oxford, UK: Oxford University Press; 1983.

74. Hung P-Y, Baird IG: From soldiers to farmers: The political geography of Chinese Kuomintang territorialization in northern Thailand. Political Geography 2017, 58:1-13.

75. Vaddhanaphuti C: The Thai state and ethnic minorities: From assimilation to selective integration. In: Ethnic Conflicts in Southeast Asia. edn. Edited by Snitwongse K, Thompson W: ISEAS-Yusof Ishak Institute; 2005: 151-166.

76. Laungaramsri P: Ethnicity and the politics of ethnic classification in Thailand. In: Ethnicity in Asia. edn. Edited by Mackerras C. London and New York: Routledge Curzon; 2003: 157-173.

77. Feingold DA: Money, Myths, and Models: opium, economics, and history on the Thai-Burma frontier. In: Opiate Drug Consumption Patterns Asia. edn. Edited by V N, RL R, PH H. Penang: The National Drug Centre, U.N./WHO Collaborating Centre for Research and Training in Drug Dependence; 1981: 146-158.

78. Feingold DA: The Hell of Good Intentions: Some Preliminary Thoughts on Opium in the Political Ecology of the Trade in Girls and Women. In: Where China Meets Southeast Asia: Social and cultural change in the border regions. edn. Edited by Evans G, Kuah K. Singapore: ISEAS-Yusof Ishak Institute; 1997.

79. Morlaeku C: Problems Concerning the Laxity of Legal Status within the Thai Highland Population. Bangkok; 2006.

80. Gray J: HIV/AID in The Hills: A Crisis Just Waiting to Happen. In: 5th International Thai Studies Conference, School of Oriental and African Studies, University of London: 1993; 1993.

81. Torugsa K, Anderson S, Thongsen N, Sirisopana N, Jugsudee A, Junlananto P, Nitayaphan S, Sangkharomya S, Brown AE: HIV epidemic among young Thai Men, 1991-2000. Emerg Infect Dis 2003, 9(7):881.

82. Razak MH, Jittiwutikarn J, Suriyanon V, Vongchak T, Srirak N, Beyrer C, Kawichai S, Tovanabutra S, Rungruengthanakit $\mathrm{K}$, Sawanpanyalert P: HIV prevalence and risks among injection and noninjection drug users in northern Thailand: need for comprehensive HIV prevention programs. JAIDS Journal of Acquired Immune Deficiency Syndromes 2003, 33(2):259-266. 
83. Celentano DD, Jittiwutikorn J, Hodge MJ, Beyrer C, Nelson KE: Epidemiology of HIV-1 infection in opiate users in Northern Thailand. Journal of acquired immune deficiency syndromes and human retrovirology: official publication of the International Retrovirology Association 1998, 17(1):73-78.

84. Wiewel E, Go V, Kawichai S, Beyrer C, Vongchak T, Srirak N, Jittiwutitikarn J, Suriyanon V, Razak M, Celentano DD: Injection prevalence and risks among male ethnic minority drug users in Northern Thailand. AIDS Care 2005, 17(1):102-110.

85. Ayuttacorn A, Tangmunkongvorakul A, Musumari PM, Srithanaviboonchai K, Jirattikorn A, Aurpibul L: Disclosure of HIV status among Shan female migrant workers living with HIV in Northern Thailand: A qualitative study. PLoS One 2019, 14(5):e0216382.

86. Feingold DA: Targeting Inclusion and Equity: Using Culturally Appropriate Communication to Reduce Risks of HIV/AIDS, Human Trafficking and Non-traditional-Drug Abuse among Ethnic Minorities. In. Manila; 2007.

87. Feingold DA: One Size Does Not Fit All: Ethno-linguistic Minorities and "Inclusive Growth.". In. Manila; 2007.

88. Kobori E, Visrutaratna S, Kada A, Wongchai S, Ono-Kihara M, Kihara M: Prevalence and correlates of sexual behaviors among Karen villagers in northern Thailand. AIDS Behav 2007, 11(4):611-618.

89. Omori K: Knowledge about AIDS and risk behaviors among hill tribes in northern Thailand. [Nihon koshu eisei zasshi] Japanese journal of public health 1999, 46(6):466-475.

90. Flaim AL: Left Out and Left Behind: The Impact of Legal Status on Educational Attainment Among Highland Ethnic Minorities in Northern Thailand. Cornell University; 2008.

91. Morlaeku C: Addressing the Remaining Legal Status Question. In. Bangkok; 2010.

92. Mukdawan S: Citizenship and Education as the Basis for National Integration of Ethnic Minorities in North Thailand. Sydney: Macquarie University; 2009.

93. Pesses A: Highland Birth and Citizenship Registration in Thailand. In: Final Report on Karen Focus Group Discussions in Chiang Mai Province. 2007.

94. Flaim A, Williams LB, Ahlquist DB: How Statelessness, Citizenship, and Out-migration Contribute to Stratification Among Rural Elderly in the Highlands of Thailand. Soc Forces 2020, 99(1):333-365.

95. Behrman JA: The effect of increased primary schooling on adult women's HIV status in Malawi and Uganda: Universal Primary Education as a natural experiment. Soc Sci Med 2015, 127:108-115.

96. Reddy M: Identity Paper/Work/s and the unmaking of legal status in Mae Sot, Thailand. AsianJLS 2015, 2:251.

\section{Figures}


Ethnicity, cultural context, \& other structural barriers

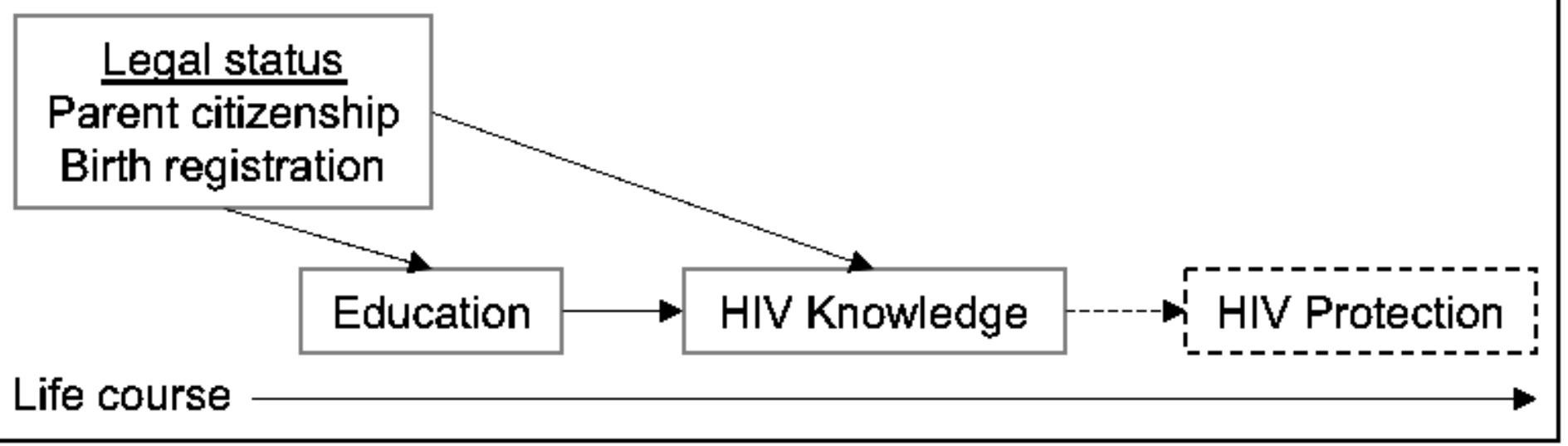

Figure 1

Mechanisms linking LS adjudication and HIV protection over life course. 


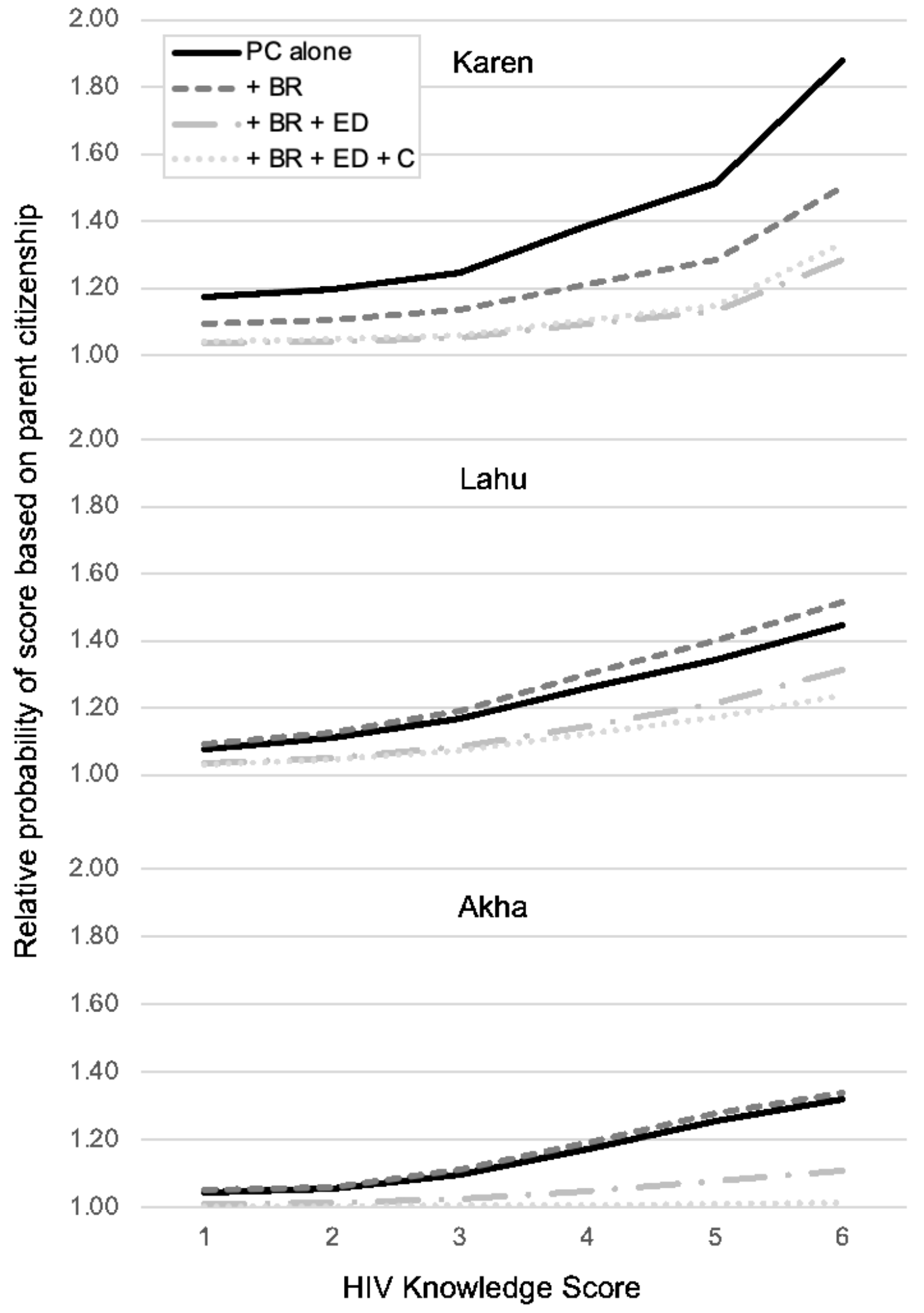

Figure 2

Probability ratios comparing HPS II respondent HIV knowledge scores by parent citizenship (PC).

\section{Supplementary Files}

This is a list of supplementary files associated with this preprint. Click to download. 
- LegalStatusSocialDeterminantHIVOnline.20200515.docx 